\title{
Evidenciação de Passivos Ambientais em Empresas de Energia Hidrelétrica
}

\author{
Environmental Liabilities Disclosure in Hydroelectric Power Companies
}

Divulgación de los Pasivos Ambientales en empresas de Energía Eléctrica

\author{
Aglaeudis Ferreira Rodrigues Campos \\ Bacharel em Ciências Contábeis \\ Universidade Federal da Paraíba \\ aglaeudis@gmail.com \\ https://orcid.org/0000-0001-9221-5778
}

Ana Lúcia de Araújo Lima Coelho

Doutora em Administração e Turismo

(PPGA/UNIVALI)

Universidade Federal da Paraíba PB

ana.coelho@academico.ufpb.br

https://orcid.org/0000-0002-0877-6351
Christiano Coelho

Doutor em Ciências Ambientais (PRODEMA/UFPB)

Universidade Federal da Paraíba PB cc@academico.ufpb.br

https://orcid.org/0000-0003-1614-5573

Maria Sueli Arnoud Fernandes
Doutora em Ciências Contábeis (Programa Multi-
institucional UnB/UFPB/UFRN)
Universidade Federal da Paraíba PB
sueliarnoud@gmail.com
https://orcid.org/0000-0002-7220-1771

\section{RESUMO}

Objetivo: verificar características da evidenciação de passivos ambientais assumidos em empresas hidrelétricas no Brasil frente à emissão de licenças ambientais.

Método: a pesquisa classifica-se como descritiva, documental e bibliográfica, com uma abordagem qualitativa. Para realização desse estudo, foram consultados o EIA/RIMA das cinco empresas de energia hidrelétrica que fazem parte do Índice de Sustentabilidade Empresarial, listadas na B3, além de suas Demonstrações Financeiras Padronizadas e os Relatórios de Sustentabilidade, referente ao período de 2012 a 2019.

Principais resultados: diante dos resultados obtidos, constatou-se que de acordo com o checklist 1 referente aos grupos de ações ambientais, os itens que foram divulgados de forma mais representativa nos relatórios das empresas de energia hidrelétrica no período de 2012 a 2019 foram os itens que tratam da Gestão de Recursos Hídricos, Educação Ambiental e Monitoramento Ambiental. Em relação ao checklist 2 (Passivos Ambientais), os itens que mais foram evidenciados pelas empresas foram as Provisões Ambientais, as Indenizações Ambientais e as Contingências Ambientais.

Contribuições: essa pesquisa contribui como auxílio na tomada de decisão dos usuários das informações contábeis, especialmente aos stakeholders. Além, de uma reflexão científica sobre o uso dos estudos ambientais. 
Aglaeudis Ferreira Rodrigues Campos; Christiano Coelho; Ana Lúcia de Araújo Lima Coelho; Maria Sueli Arnoud Fernandes.

Relevância: por meio desse estudo, nota-se a necessidade e a importância da evidenciação das práticas ambientais nos relatórios financeiros e de sustentabilidade de empresas, em especial as do setor de energia hidrelétrica. Os achados apontam que há necessidade de as empresas melhorarem as evidenciações acerca das informações ambientais reforçando o que se apresenta em outros estudos. Outro destaque é que, apesar do arcabouço teórico e legal existente para a realidade brasileira está aderente às normas internacionais, a evidenciação de passivos ambientais apresenta uma fragilidade de textos normativos que estão facultando a evidenciação de passivos ambientais em relatórios contábeis e suas respectivas notas explicativas.

Palavras-chave: Passivos Ambientais. Evidenciação Ambiental. Energia Hidrelétrica.

\section{ABSTRACT}

Objective: the present work aims to verify the characteristics of the disclosure of environmental liabilities assumed in hydroelectric companies in Brazil against the issuance of environmental licenses.

Method: the research is classified as descriptive, archival and bibliographical, with a qualitative approach. To carry this study out, the EIA/RIMA of the five hydroelectric power companies that are part of the Corporate Sustainability Index, listed on B3, were consulted, in addition to their Standardized Financial Statements and Sustainability Reports, for the period from 2012 to 2019.

Main results: according to the obtained results, it was found that, according to checklist 1 regarding the groups of environmental actions, the items that were most representatively disclosed in the reports of hydroelectric power companiesfor the period from 2012 to 2019 were the ones dealing with Water Resources Management, Environmental Education and Environmental Monitoring. Regarding checklist 2 (Environmental Liabilities), the items that were most highlighted by the companies were Environmental Provisions, Environmental Indemnities and Environmental Contingencies.

Contributions: this research contributes as an aid to the decision-making of users of accounting information, especially stakeholders. In addition, it is scientific reflection on the use of environmental studies.

Relevance: this study highlights the need and importance of disclosing environmental practicesin companies' financial and sustainability reports, especially those in the hydroelectric energy sector. The findings imply that there is a need for companies to improve disclosures about environmental information, reinforcing what is presented in other studies. Another highlight is that, despite the existing theoretical and legal framework for the Brazilian reality, which adheres to international standards, the disclosure of environmental liabilities presents a weakness in normative texts that are enabling the disclosure of environmental liabilities in accounting reports and their respective explanatory notes.

Keywords: Environmental Liability. Environmental Disclosure. Hydro-electric Energy. 
Aglaeudis Ferreira Rodrigues Campos; Christiano Coelho; Ana Lúcia de Araújo Lima Coelho; Maria Sueli Arnoud Fernandes.

\section{RESUMEN}

Objetivo: el presente trabajo tiene como objetivo verificar las características de la divulgación de los pasivos ambientales asumidos en las empresas hidroeléctricas en Brasil frente a la emisión de licencias ambientales.

Método: la investigación se clasifica en descriptiva, documental y bibliográfica, con un enfoque cualitativo. Para la realización de este estudio se consultó el EIA / RIMA de las cinco empresas hidroeléctricas que forman parte del Índice de Sustentabilidad Corporativa, listadas en B3, además de sus Estados Financieros Estandarizados e Informes de Sustentabilidad, para el período de 2012 a 2019.

Principales resultados: ante los resultados obtenidos, se encontró que, de acuerdo con el checklist 1 de los grupos de acciones ambientales, los rubros que fueron divulgados de manera más representativa en los informes de las empresas hidroeléctricas en el período 2012 a 2019 que tratan de la Gestión de Recursos Hídricos, Educación Ambiental y Monitoreo Ambiental. En cuanto al checklist 2 (Pasivos Ambientales), los rubros más destacados por las empresas fueron Provisiones Ambientales, Indemnizaciones Ambientales y Contingencias Ambientales.

Contribuciones: esta investigación contribuye como una ayuda en la toma de decisiones por parte de los usuarios de la información contable, especialmente las partes interesadas. Además de la reflexión científica sobre el uso de estudios ambientales

Relevancia: este estudio destaca la necesidad e importancia de divulgar las prácticas ambientales en los informes financieros y de sostenibilidad de las empresas, especialmente las del sector de energía hidroeléctrica. Los hallazgos indican que existe la necesidad de que las empresas mejoren la divulgación de información ambiental, reforzando lo presentado en otros estudios. Otro destaque es que, a pesar del marco teórico y legal existente para la realidad brasileña, que se adhiere a los estándares internacionales, la divulgación de pasivos ambientales presenta una debilidad en los textos normativos que están permitiendo la divulgación de pasivos ambientales en los informes contables y sus respectivas notas explicativas.

Palabras clave: Pasivos ambientales. Divulgación medioambiental. Energía hidroeléctrica.

\section{INTRODUÇÃO}

Os impactos ambientais causados pela interferência humana é um tema que pode ser considerado multidisciplinar. A obrigação de realizar uma gestão ambiental para mitigar e/ou compensar o meio ambiente está relacionada com ações para favorecer a qualidade de vida do ser humano no meio ambiente. No Brasil, as atividades econômicas de empresas consideradas potencialmente poluidoras, e que, consequentemente, causem degradação ambiental, assumem a responsabilidade legal de realizar um conjunto de ações de gestão para obter ou manter suas licenças ambientais. Esse licenciamento é destinado a viabilizar, sob o controle do Estado, atividades e/ou empreendimentos que se utilizam de recursos ambientais, de forma efetiva ou potencialmente poluidores, analisando uma relação entre impactos positivos e negativos com a obrigação de uma gestão ambiental (Conama, 1997).

Prosppectus - Perspectivas Qualitativas em Contabilidade e Organizações. João Pessoa. v. 1, n. 1, p. 108 135, jul/2021. 
Aglaeudis Ferreira Rodrigues Campos; Christiano Coelho; Ana Lúcia de Araújo Lima Coelho; Maria Sueli Arnoud Fernandes.

Na década de 1990, um estudo junto ao Ministério de Energia e Meio Ambiente, realizado no Canadá (Li, Richardson \& Thornton, 1997), trouxe um suporte empírico contábil para divulgações a serem realizadas por empresas que causam degradação ambiental. Os autores, a partir de um modelo teórico, apontaram implicações para empresas divulgarem ou não informações sobre seus passivos ambientais. A primeira delas diz respeito a discricionariedade de gestores. A ausência ou a possibilidade de julgamentos sobre o que e como divulgar sugeriria que nem sempre todas as empresas cumprirão os padrões de divulgação. Outra implicação apontada pelos autores era fomentar a divulgação de informações privadas das empresas por órgãos não contábeis. Nesse sentido, eles afirmaram que há um direcionamento para encorajar a divulgação de dados voluntários sobre passivos ambientais em órgãos públicos. Por fim, eles apontaram que, caso haja um aumento de exigências de órgãos de controle, na perspectiva de preservação e/ou conservação ambiental, ocorrerá um desencorajamento pela divulgação de passivos ambientais. Isso estaria relacionado com a incerteza e o risco de incorrer em custos proprietários ou políticos.

Eckert, Corci Neto e Boff (2015) acentuam que, as empresas no Brasil vêm aumentando suas práticas de responsabilidade ambiental. Tais práticas estão ocorrendo por alguns fatores, seja por pressão da sociedade em geral ou como parte das políticas governamentais. Segundo a Lei 9.605/1998, as licenças ambientais materializam a autorização que o empreendimento precisa ter para exercer sua atividade, neste documento são reveladas as obrigações que devem ser assumidas e o seu descumprimento poderá causar ruptura em sua atividade econômica, acarretando multas e suspensão da licença.

Mais recentemente, no início do Século XXI, estudos internacionais mostram que a evidenciação de informações ambientais ainda carece de melhorias (Por exemplo, Negash \& Lemma 2020; Paananen, Runesson \& Samani, 2021; Senn \& Giordano-Spring, 2020). Apesar de um aumento de práticas ambientais, estudos sinalizam que ainda são baixos os níveis de evidenciação relacionados a divulgação nos relatórios a respeito de passivos ambientais. Para Negash e Lemma (2020), em um estudo realizado na África do Sul, há uma tendência crescente de divulgação dos passivos ambientais pelas empresas. Entretanto, o nível de divulgação para estimar passivos ambientais ainda pode ser considerado baixo.

No mesmo direcionamento, Senn e Giordano-Spring (2020), numa pesquisa realizada na França, revela que o principal resultado é que a divulgação de informações ambientais ainda se encontram em estágio primário. Segundo eles, o baixo nível de divulgação é consequência da fragilidade nas definições e orientações dos regulamentos. Nesse caso, isso permite as diversas interpretações por parte dos agentes na elaboração dos relatórios anuais das empresas.

Outro estudo com empresas europeias, a partir de uma abordagem de normas internacionais de contabilidade, conduzido por Paananen et al. (2021), traz a diversidade nas práticas de divulgação em todos os setores e regiões. De acordo com os autores, 
Aglaeudis Ferreira Rodrigues Campos; Christiano Coelho; Ana Lúcia de Araújo Lima Coelho; Maria Sueli Arnoud Fernandes.

embora haja uma tendência de divulgação crescente, o nível de divulgação permanece baixo.

No que se refere à realidade brasileira, os atores, Sociedade, Mercado e Estado têm, no licenciamento ambiental, um instrumento de comando e controle de política pública ambiental para que atividades sejam consideradas econômica e socialmente viáveis e ambientalmente sustentáveis (Coelho, 2019). Para Farias (2017), o licenciamento ambiental deve promover um desenvolvimento mais sustentável dos países, no qual os recursos naturais disponíveis são utilizados com racionalidade. E para que exista um controle da ação do homem no meio ambiente se faz necessária uma participação mais efetiva, ou seja, uma intervenção do Estado no processo de desenvolvimento.

Nesse contexto multidisciplinar, a Contabilidade pode contribuir com informações a seus diversos usuários. Ela está inserida no debate ambiental como aliada às empresas na divulgação de uma atitude ambientalmente responsável (Novis \& Ferreira, 2017). Considerando que ações de gestão ambiental provocam mutações no patrimônio das entidades, uma Contabilidade Ambiental pode produzir informações úteis ao processo decisório de usuários internos e externos (Ferreira, 2011).

Nesse ínterim, esse estudo, especificamente trata dos passivos ambientais os quais podem ser entendidos como os recursos econômicos que serão desembolsados pela empresa relativos a questões ambientais atreladas às ações da entidade, passadas ou em ocorrência, nesse meio, sendo dedicados à preservação, proteção e recuperação do meio ambiente com o objetivo de contribuir para um desenvolvimento sustentável ou para reparar práticas danosas causadas à natureza (Por exemplo, Carvalho, 2008; Novis \& Ferreira, 2017, como citado em Marques, 2016; Ribeiro 2010).

Além disso, a contabilidade ambiental se apresenta como aliada às empresas na divulgação de uma atitude ambientalmente responsável (Novis \& Ferreira, 2017). Segundo Ferreira (2011) a contabilidade especificamente a ambiental congrega informações que descrevem "as ações de uma entidade sobre o meio ambiente que modifiquem seu patrimônio" (p. 112).

De acordo com a Resolução CONOMA n. ${ }^{-} 1$ de 23 de janeiro de 1986, as empresas devem emitir um documento para criar expectativa perante à sociedade onde atuam, a qual passarão a cumprir alguns compromissos ambientais. Esses documentos são o Estudo de Impacto Ambiental (EIA) e o Relatório de Impacto Ambiental (RIMA).

O EIA é um documento técnico que além de listar os danos causados em cada fase da atividade que se pretende dar início e suas medidas de mitigação, aborda quais as consequências positivas da atividade, as alternativas tecnológicas e de localização da mesma, confrontando-as com a hipótese de não execução do projeto, e faz um “diagnóstico ambiental da área de influência do projeto completa descrição e análise dos recursos ambientais e suas interações, tal como existem, de modo a caracterizar a situação ambiental da área, antes da implantação do projeto". Já o RIMA é um resumo do EIA, com uma linguagem de mais fácil entendimento, e que deve ser de alcance de 
Aglaeudis Ferreira Rodrigues Campos; Christiano Coelho; Ana Lúcia de Araújo Lima Coelho; Maria Sueli Arnoud Fernandes.

todos os que o quiserem consultar. (Novis \& Ferreira, 2017). É importante ressaltar que o EIA é elaborado antes do projeto e o RIMA vem em seguida, depois da execução.

Diante do exposto, este estudo busca responder a seguinte problemática: Como se caracteriza a evidenciação de passivos ambientais em empresas de energia hidrelétrica no processo de licenciamento ambiental brasileiro? O objetivo geral da presente pesquisa é analisar características da evidenciação de passivos ambientais nas empresas hidrelétricas assumidos na emissão de licenças ambientais.

Esse estudo justifica-se, pois, existe a necessidade de melhorar a forma como são evidenciadas as informações ambientais para que, de fato, os investidores e a sociedade possuam informações transparentes e completas. Tendo em vista que existe uma ausência em pesquisas sobre o tema passivos ambientais, este estudo escolheu empresas de energia hidrelétricas integrantes do Índice de Sustentabilidade Empresarial (ISE) por estas possuírem reconhecido comprometimento com o desenvolvimento sustentável e responsabilidade social, em seu modelo de negócios. Ademais, a responsabilidade socioambiental constitui um aspecto relevante no contexto empresarial por ser uma oportunidade para que as organizações apresentem uma boa imagem perante o público, na medida em que desenvolvem práticas que promovam o equilíbrio nas esferas econômicas, social e ambiental (Silva et al., 2017).

O período da coleta de dados foi de 2012 a 2019, a fim de verificar características de evidenciação dos passivos ambientais. O período escolhido iniciando-se a partir do ano de 2012, justifica-se porque nesse ano houve um crescimento significativo do consumo de energia, chegando a representar (3,6\%) em relação ao ano de 2011. Por causa desse aumento, implicou em uma maior necessidade de recursos naturais, bem como em um aumento de seus impactos no meio ambiente (Ferreira, 2018).

Dessa forma, Berthelot, Cormier e Magnan (2003) enfatizam a relevância da divulgação de informações ambientais, considerando o disclosure (evidenciação) importante para tomada de decisão dos stakeholders. Deste modo, esta pesquisa tende a contribuir com a evolução da ciência contábil, destacando por meio dos Relatórios de Impacto Ambiental (RIMA), as informações ambientais, onde estão relacionados com o objeto da contabilidade, o patrimônio. Portanto, ressalta-se a importância de utilizar os estudos ambientais, para que sirva como fonte de elaboração dos relatórios contábeis (Coelho, 2010). Por fim, vale salientar que é pública a informação de danos ambientais causados pelas empresas, dessa forma, estudos como este buscam elucidar a relação com o meio ambiente as empresas e a sociedade (Sabino, Ferreira \& Ferreira, 2020).

As demais seções do artigo trazem um referencial teórico, compreendendo, (i) debate sobre a relação de uma gestão ambiental frente ao processo de licenciamento ambiental no Brasil, (ii) abordagem acerca de aspectos teóricos sobre evidenciação de passivos ambientais e (iii) estudos anteriores. Na sequência, mostra o detalhamento dos procedimentos adotados neste estudo e, posteriormente, a apresentação e discussão dos resultados da pesquisa. Finaliza-se o artigo com as reflexões e destaques da contribuição do estudo, limitações e indicações para futuras pesquisas.

Prosppectus - Perspectivas Qualitativas em Contabilidade e Organizações. João Pessoa. v. 1, n. 1, p. 108 $135, \mathrm{jul} / 2021$. 
Aglaeudis Ferreira Rodrigues Campos; Christiano Coelho; Ana Lúcia de Araújo Lima Coelho; Maria Sueli Arnoud Fernandes.

\section{REFERÊNCIAL TEÓRICO}

\subsection{Gestão e Licenciamento Ambiental}

Com o aumento da tecnologia, e a indução ao consumo, dentre outras variáveis, a relação do homem com o ecossistema tornou-se cada vez mais desequilibrada. Portanto, surge a necessidade de gerir os recursos naturais, buscando compreender a capacidade que pode ser suportada pelo ecossistema. Nesse contexto, atividades potencialmente poluidoras necessitam demonstrar desempenho adequado de sua gestão ambiental para requerer ou manter licenças ambientais exigidas pela legislação (Coelho, 2019).

A preocupação com a sustentabilidade tem levado as empresas a ponderarem suas práticas e ações de maneira responsável, tendo como objetivo reduzir os impactos ambientais que são ocasionados pelas suas atividades empresárias (Santos, Braga \& Cavalcanti, 2019). Para tanto, as práticas de uma gestão sustentável podem ajudar as organizações a evitarem perdas, melhorando a qualidade das suas operações, resultando, com isso, em ganhos para todos os envolvidos (Santos, Silva, Souza \& Souza, 2001).

O gerenciamento ambiental, portanto, é uma abordagem estruturada e sistemática para gerenciar e medir os impactos ambientais organizacionais (Xie, Zang \&Qi, 2016). Para Barbieri (2017), o gerenciamento ambiental é um conjunto de atividades de direção, controle, planejamento, alocação de recursos e outras ações que tenham como objetivo reduzir e/ou eliminar os danos causados ao meio ambiente.

Sánchez (2008), afirma que gestão ambiental é um conjunto de medidas para prevenir, atenuar ou compensar os impactos e riscos ambientais, além de proporcionar medidas voltadas para valorizar os impactos positivos. Ferreira (2011), por sua vez, comenta que a contabilidade pode ser um importante mecanismo para a gestão ambiental, à medida que considera aspectos do desempenho financeiro e econômico.

Kraemer (2011), enfatiza que as vantagens de se ter uma boa gestão estão relacionadas a criação de uma imagem "verde", facilitando a empresa acesso a novos mercados; redução dos custos de remediação e acidentes com o meio ambiente; conservação de recursos naturais e energia; atividades racionalizadas; redução de perdas e desperdícios; maior economia de escala com facilidade de acesso a créditos e financiamentos.

O caminho para se ter uma gestão ambiental de qualidade incluem diretrizes e princípios, que foram estabelecidos por diversas entidades internacionais, permitindo que as atividades sistemáticas de prevenção do meio ambiente nas organizações sucedam da melhor forma possível (Costa Filho \& Rosa, 2017). Na tabela 1 estão descritos modelos de gestão ambiental. 
Aglaeudis Ferreira Rodrigues Campos; Christiano Coelho; Ana Lúcia de Araújo Lima Coelho; Maria Sueli Arnoud Fernandes.

Tabela 1

Modelos de gestão ambiental

\begin{tabular}{|c|c|}
\hline $\begin{array}{c}\text { Modelo de gestão } \\
\text { ambiental }\end{array}$ & Descrição \\
\hline $\begin{array}{l}\text { Responsible Care } \\
\text { (Atuação } \\
\text { Responsável) }\end{array}$ & $\begin{array}{l}\text { É um programa voluntário criado pela associação canadense da Industria, em meados } \\
\text { dos anos } 80 \text {, que objetiva estabelecer princípios de atuação ambientalmente responsável } \\
\text { para o setor de indústria química. No Brasil, a atuação responsável está a cargo da } \\
\text { Associação Brasileira da Industria Química (ABIQUIM). }\end{array}$ \\
\hline $\begin{array}{l}\text { Modelo Winter } \\
\text { (Sistema Integrado de } \\
\text { Gestão Ambiental) }\end{array}$ & $\begin{array}{l}\text { Modelo voluntário de gestão ambiental, desenvolvido por George Winter por volta de } \\
\text { 1989, na Alemanha. A partir de então, as empresas perceberam que atuar de forma } \\
\text { ambientalmente responsável tinha como significado uma vantagem competitiva. A } \\
\text { partir desse momento, desenvolveram seus sistemas de gestão em conciliação com a } \\
\text { causa ambiental. }\end{array}$ \\
\hline $\begin{array}{r}\text { Coalisio } \\
\text { Environm } \\
\text { Responsible } \\
(\text { CERI } \\
\end{array}$ & $\begin{array}{l}\text { Uma organização que não possui fins lucrativos, criou esse modelo para encorajar as } \\
\text { empresas a desenvolverem programas que tinham como objetivo prevenir a } \\
\text { degradação ambiental. Logo após o acidente no Alaska com o Exxon Valdez em 1989, o } \\
\text { programa lançou uma sequência de princípios, visando a proteção ambiental. }\end{array}$ \\
\hline $\begin{array}{l}\text { Eco-Management and } \\
\text { Audit Scheme (EMAS) }\end{array}$ & $\begin{array}{l}\text { Sistema europeu de Ecogestão e Auditorias. Esse sistema foi estabelecido pelo } \\
\text { regulamento } 1936 / 93 \text { da comissão da Comunidade Europeia, onde estabeleceu critérios } \\
\text { para certificações ambientais de processos industriais. Seguidamente, foram } \\
\text { acrescentados a esses critérios um sistema de gestão de auditorias. }\end{array}$ \\
\hline $\begin{array}{c}\text { Norma Britânica BS } \\
7750\end{array}$ & $\begin{array}{l}\text { Essa norma foi criada em } 1992 \text { pelo Instituto Britânico de Normalização que } \\
\text { desenvolveu um documento para as certificações ambientais, passando a exigir as } \\
\text { organizações elaboração de políticas e objetivos estabelecidos no trato com o meio } \\
\text { ambiente. }\end{array}$ \\
\hline $\begin{array}{l}\text { Produção Mais Limpa } \\
\qquad(P+L)\end{array}$ & $\begin{array}{l}\text { Um programa das Nações Unidas para o meio ambiente. É uma abordagem de gestão } \\
\text { preventiva de maneira integrada a processos, produtos e serviços, tendo como objetivo } \\
\text { melhorar a eficiência ecológica da empresa. }\end{array}$ \\
\hline $\begin{array}{l}\text { ISO } 14000 \text { - Normas } \\
\text { Internacionais para } \\
\text { Gestão Ambiental }\end{array}$ & $\begin{array}{l}\text { Um padrão voluntário, que teve início na década de 1990, pela International Organization } \\
\text { for Standardization com sede na Suíça. Seu objetivo é proporcionar as organizações } \\
\text { ferramentas para o sistema de gestão eficaz, tendo como possibilidade a integração a } \\
\text { outros sistemas de gestão e assim permitir que os objetivos ambientais e econômico } \\
\text { sejam alcançados. }\end{array}$ \\
\hline
\end{tabular}

Fonte: Barbieri (2011); Shigunov, Campos e Shigunov (2009); Seiffert (2010).

Dos modelos apresentados, o mais conhecido é o International Organization for Standardization (ISO) 14.000. Para obter essa certificação é preciso que a empresa institua um documento de Sistema de Gestão Ambiental (SGA), conforme os requisitos descritos na seção 4 da ISO 14.001. Assim como a ISO para qualidade série 9000, a certificação ISO na área ambiental dá a empresa detentora uma excelente reputação junto à comunidade empresarial facilitando um relacionamento, abrindo portas para negócios no país e no exterior (Costa Filho \& Rosa, 2017).

Com relação as licenças ambientais, estas estão diretamente ligadas as práticas de gestão ambiental. Desta forma, a responsabilidade civil em termos ambientais é atribuída aquela empresa que provocou o dano ambiental. A lei 6.938 de 31 de agosto de 1981, dispõe sobre a Política Nacional do Meio Ambiente (PNMA), estabelecendo no seu artigo 10 que empreendimentos e atividades que façam uso de recursos ambientais e sejam efetivas ou altamente poluidoras ou capazes de causar degradação ambiental

Prosppectus - Perspectivas Qualitativas em Contabilidade e Organizações. João Pessoa. v. 1, n. 1, p. 108 $135, \mathrm{jul} / 2021$. 
Aglaeudis Ferreira Rodrigues Campos; Christiano Coelho; Ana Lúcia de Araújo Lima Coelho; Maria Sueli Arnoud Fernandes.

dependerão do licenciamento ambiental para a construção, instalação, funcionamento e ampliação. Segundo Farias et al. (2017), licenciamento ambiental é “[...] o mais importante mecanismo estatal de defesa e preservação do meio ambiente" (p.106).

O licenciamento ambiental é um ato administrativo em que um órgão ambiental competente, no Brasil, o Instituto Brasileiro do Meio Ambiente e dos Recursos Naturais Renováveis (IBAMA) estabelece as condições, restrições e medições, condicionadas a medidas de controle ambiental, no qual os empreendedores devem obedecer, sendo pessoa física ou jurídica, de acordo com resolução 237/1997 do Conselho Nacional do Meio Ambiente (CONAMA).

Sánchez (2015), enfatiza que o licenciamento ambiental, tem sido uma intervenção estatal, que contribui para a redução de impactos que são causados por atividades potencialmente poluidoras. Esse licenciamento é composto por três fases: Licença prévia (LP), Licença de Instalação (LP), e a licença de Operação (LO). Lemos (2008) explica que o não cumprimento das regras previstas de licenciamento, pode resultar em outras sanções, multas, proibição de fabricação e ou comércio de produtos, e fechamento da atividade. De acordo com o Art. 8ำ da Resolução CONAMA no 237 (1997):

I - Licença Prévia (LP) - concedida na fase preliminar do planejamento do empreendimento ou atividade aprovando sua localização e concepção, atestando a viabilidade ambiental e estabelecendo os requisitos básicos e condicionantes a serem atendidos nas próximas fases de sua implementação;

II - Licença de Instalação (LI) - autoriza a instalação do empreendimento ou atividade de acordo com as especificações constantes dos planos, programas e projetos aprovados, incluindo as medidas de controle ambiental e demais condicionantes, da qual constituem motivo determinante;

III - Licença de Operação (LO) - autoriza a operação da atividade ou empreendimento, após a verificação do efetivo cumprimento do que consta das licenças anteriores, com as medidas de controle ambiental e condicionantes determinados para a operação.

No parágrafo único do Art. 8º esta Resolução, ainda menciona “As licenças ambientais poderão ser expedidas isolada ou sucessivamente, de acordo com a natureza, características e fase do empreendimento ou atividade".

Para Bim (2016), ao submeter determinada atividade ao licenciamento ambiental, o empreendimento que aprovar degradação ao ambiente, causando danos ambientais mais expressivos, deve desenvolver um estudo de Impacto Ambiental (EIA), posteriormente, subsidiado pelo Relatório de Impacto ao Meio Ambiente (RIMA). A este respeito, a Resolução CONAMA n.o 1 de 23 de janeiro de 1986, Artigo 2, destaca que o licenciamento das atividades modificadoras do meio ambiente dependerá de elaboração de Estudo de Impacto Ambiental (EIA) como também de um RIMA. 
Aglaeudis Ferreira Rodrigues Campos; Christiano Coelho; Ana Lúcia de Araújo Lima Coelho; Maria Sueli Arnoud Fernandes.

Segundo o CONAMA 01/86 o EIA é um documento técnico que deve conter todas as alternativas tecnológicas e de localização do empreendimento, bem como listando os tipos de impactos sejam eles, "positivos e negativos", "benefícios e adversos", "diretos e indiretos", "imediatos e a médios e longo prazos", e "temporários e permanente". Para cada fase de atividade deve descrever as medidas mitigadoras dos impactos negativos, definindo a área direta ou indiretamente que forem afetados pelos impactos. Destaca-se ainda para fins deste estudo, que o diagnóstico ambiental a ser apresentado deve, dentre outros aspectos, elaborar programas de acompanhamento e monitoramento dos impactos considerados positivos e negativos.

O RIMA, ainda segundo o CONAMA 01/86, é um resumo do EIA. O RIMA, em linguagem de fácil entendimento, deve relatar as vantagens e desvantagens do empreendimento e as consequências da sua implementação. Este Relatório pode ser apresentado em audiência pública para ser discutido com aqueles que estão diretamente sendo impactados no entorno dos empreendimentos. Madruga Filho et al. (2019) dizem que a manifestação das comunidades envolvidas e que são afetadas pela instalação de um determinado empreendimento, geram efeitos diversos, como os questionamentos e motivações no momento da elaboração do RIMA. As audiências públicas tendem a favorecer o melhoramento e valorização do projeto a ser desenvolvido em uma determinada região.

\subsection{Passivos Ambientais e Evidenciação}

Os passivos ambientais podem surgir quando a empresa tem o ônus de prevenir, retificar ou reduzir, remediar ou proteger, quando existe um dano ecológico em consequência de uma obrigação legal, contratual, política, voluntária e estratégica (Paiva, 2006; Vellani, 2008). Dentro desse conceito o passivo ambiental tem sido conceituado como toda obrigação contraída de forma voluntária ou não, destinada a aplicação em ações de controle, recuperação e preservação do meio ambiente (Melo, Tinoco \& Fernandes, 2010).

Os passivos ambientais passaram a ser conhecidos por uma conotação mais negativa, onde as empresas que possuem, agrediram ou violaram de forma significativa o meio ambiente, gerando pagamentos de vultosas quantias de indenizações, penalidades e multas, para recuperar os danos causados. No entanto, estes passivos não são apenas negativos, eles podem provir de responsabilidades, decorrentes da manutenção de um sistema de gerenciamento ambiental, voltados para a sustentabilidade. (Por exemplo, Lima Filho, Bruni \& Gomes, 2013; Mangonaro, 2010; Melo et al., 2010).

Segundo Tinoco \& Kraemer (2011) existem quatro tipos de obrigações decorrentes do passivo ambiental: (a) Legais, estas surgem de um contrato, legislação ou outro instrumento de lei; (b) Implícitas, a empresa assume um compromisso devido a práticas do passado, políticas divulgadas ou declarações feitas; (c) Construtivas, são as que a empresa se propõe a cumprir espontaneamente, normalmente, são empresas preocupadas com sua responsabilidade social; e (d) Justas: são aquelas que refletem a Prosppectus - Perspectivas Qualitativas em Contabilidade e Organizações. João Pessoa. v. 1, n. 1, p. 108 135, jul/2021. 
Aglaeudis Ferreira Rodrigues Campos; Christiano Coelho; Ana Lúcia de Araújo Lima Coelho; Maria Sueli Arnoud Fernandes.

consciência de responsabilidade social, ou seja, a empresa cumpre em razão de fatos éticos e morais. Ainda conforme os autores supramencionados, os passivos ambientais podem ser classificados como normais, quando podem ser controlados pela organização, e está dentro do fluxo das operações e anormais quando a situação foge ao controle da empresa e fora do contexto das operações.

Fernandes, Santiago e Peixoto (2012) compreende que a mensuração é a parte mais difícil da contabilização, sendo necessário atribuir valor ao dano ambiental gerado pela empresa, no entanto, os recursos naturais são finitos. Neste sentido, as técnicas para identificar são escassas e o valor dos recursos que servem para minimizar a degradação ambiental tem limitações para quantificação. Corroborando com Ferreira (2011) que enfatiza em seus estudos que atribuir valor é um processo crítico da contabilidade, pois, este ambiente de incertezas, provém de desconhecimentos de métodos que podem ser utilizados.

Ademais, Tinoco \& Kraemer (2011) afirmam que para mensurar um passivo ambiental a organização deve considerar alguns fatores: (i) custos complementares da reparação ambiental; (ii) custos com salários e encargos dos trabalhadores no processo de restauração do meio ambiente atingido; (iii) obrigações de controle após a reparação do desastre ambiental; desenvolvimento de novas tecnologias. Ainda conforme Tinoco e Kraemer (2011), o passivo reconhecido nas demonstrações contábeis, deve ser provável e estimado, caso a empresa possua alguma dificuldade para atribuir um valor estimável, deverá ser provisionado em notas explicativas.

A entidade pode verificar a existência de seus passivos ambientais, assim como sua base de mensuração através das fontes externas como o EIA ou RIMA, ou fontes internas como o Termo de Ajustamento de Conduta (TAC) ou Compromisso de ajustamento de Conduta (CAC), outras fontes devem ser consultadas para a verificação dos passivos ambientais (Marques, 2016).

No que se refere a evidenciação, Iudícibus, Martins e Gelbke (2009) diz que se deve "apresentar informação quantitativa e qualitativa de maneira ordenada, deixando o menos possível para ficar de fora dos demonstrativos formais, a fim de propiciar uma base adequada de informação para o usuário" (p. 116). Devendo ser evidenciadas as informações que são consideradas relevantes de maneira adequada, justas e plenas, onde devem ser completas, e a evidenciação ou disclosure deve tornar os demonstrativos contábeis significativos, e possíveis de serem compreendidos. A divulgação ambiental é um mediador entre o público e as partes interessadas pela responsabilidade ambiental das empresas (Baral \& Pokharel, 2017). Barcelos, Tassigny, Oliveira, Almeida e Frota (2016) afirmam que a evidenciação ambiental consiste em um conjunto de informações no qual são evidenciados o passado, presente e futuro da entidade, contatando e esclarecendo o desempenho e gestão dos recursos ambientais. Por meio da divulgação, as empresas podem mostrar aos usuários, por exemplo, que as atividades e práticas ambientais realizadas por elas não agridem o meio ambiente (Lu \& Abeysekera, 2017).

No Brasil, a divulgação ambiental não é obrigatória, no entanto, o parecer de orientação no. 15/87 da Comissão de Valores Mobiliários (CVM), indica que as Prosppectus - Perspectivas Qualitativas em Contabilidade e Organizações. João Pessoa. v. 1, n. 1, p. 108 135, jul/2021. 
Aglaeudis Ferreira Rodrigues Campos; Christiano Coelho; Ana Lúcia de Araújo Lima Coelho; Maria Sueli Arnoud Fernandes.

evidenciações ambientais estejam no relatório da Administração; na norma e procedimento de Auditoria nº. 11 do Instituto dos Auditores Independentes do Brasil (IBRACON), estabelecem que os ativos e passivos ambientais devem ser registrados nos demonstrativos contábeis; a Norma Brasileira de Contabilidade (NBC T-15) no item no..15 infere que todos os itens devem ser evidenciados, como por exemplo: investimentos, e gastos com manutenção nos processos operacionais para a melhoria do meio ambiente, quantidade de processos ambientais, judiciais e administrativos movidos contra a entidade e entre outros.

A evidenciação pode ocorrer de duas formas, a compulsória que se dar por informações prestadas em decorrência de exigências legais dos órgãos reguladores e entidades da classe; ou de forma voluntaria onde todas as informações são prestadas sem obrigações legais de evidenciação, portanto, a primeira forma é a que mais ocorre (Por exemplo, Beuren, Hein \& Boff, 2011; Correa, Gonçalves \& Moraes, 2015; Marquezan, Seibert, Bartz, Barbosa \& Alves, 2015).

Como as informações ambientais são de interesse de todos os grupos de usuários e afetam, direta ou indiretamente, o patrimônio da organização, é seu dever contábil divulgar essas informações, servindo assim como uma ferramenta útil para controlar e fornecer melhores decisões sobre suas atividades. (Kasim, 2017).

\subsection{Estudos Anteriores}

Estudo como o de Coelho, Coelho e Dorow (2010) tiveram como objetivo investigar como os passivos ambientais das atividades produtoras de energia hidrelétrica foram evidenciados nos Relatórios de Impacto Ambiental (RIMA). Eles analisaram trinta Estudos Ambientais de atividades produtoras de energia hidrelétrica, que representa aproximadamente $(15,5 \%)$ em relação à população; entrevistaram sete analistas ambientais da Fundação do Meio Ambiente (FATMA), no Estado de Santa Catarina; além de gravarem as audiências públicas dessas atividades.

Os referidos autores mencionaram o princípio do poluidor pagador e afirmaram que as ações de reparação dos impactos ambientais descritas no RIMA são passivos ambientais e devem ser reparados pela empresa que os causou. Eles ainda complementam que do ponto de vista contábil não é na apresentação do EIA/RIMA que devem ser evidenciados os passivos, mas somente na emissão da licença de instalação, e ainda de modo mais específico nas condicionantes ambientais.

O estudo de Carvalho (2012) buscou relacionar as medidas mitigadoras de EIA de empresas constituídas judicialmente sob a forma de sociedade por ações no Estado de Piauí. Em seus resultados a autora manifesta seu entendimento ao apresentar que as empresas possuem variados instrumentos de comunicação no qual permite demostrar relações internas e externas. Portanto, a autora enfatiza que a contabilidade pode evidenciar as relações econômicas, sociais tendo interação com o meio ambiente, onde por meio de registros demonstrativos, pode apresentar a posição do seu patrimônio. 
Aglaeudis Ferreira Rodrigues Campos; Christiano Coelho; Ana Lúcia de Araújo Lima Coelho; Maria Sueli Arnoud Fernandes.

A pesquisa de Benetti, Benneti, Braun, Oro e Utzig (2014) teve como objetivo verificar o nível de evidenciação das Subvenções e Assistências Governamentais das empresas que integram os setores da Bm\&fBovespa em conformidade com $o$ Pronunciamento Técnico CPC 07. Os resultados encontrados pelos autores apontam que dos itens analisados, os que apresentaram maior evidenciação tratam da evidenciação da política contábil adotada pela entidade para as subvenções governamentais. Os autores ainda verificaram que que ocorreu a evidenciação de subvenções e assistências governamentais, com predomínio nos setores de Consumo Cíclico, Materiais Básicos e Utilidade Pública, porém, as empresas efetuaram a evidenciação de forma satisfatória, e atendendo de forma parcial o Pronunciamento Técnico CPC 07 (2010).

Por sua vez, a investigação científica de Novis e Ferreira (2017) buscaram analisar o EIA/RIMA da UHE de Belo Monte e verificar se os passivos ambientais listados nesse documento estão sendo divulgados nas demonstrações financeiras da empresa. Em seus resultados encontraram que apesar da empresa apresentar o EIA/RIMA para o empreendimento Belo Monte e de ali estarem evidenciados todos os impactos ambientais bem como as ações para diminuir e compensar esses impactos, ela não apresenta adequadamente essas informações, apresentando somente algumas ações nos Relatórios Anual e Socioambiental, mas que não têm referência cruzada com as Demonstrações, ou seja, não foi possível identificar se esses compromissos, com características de passivo foram reconhecidos.

Além disso, que apesar da empresa apresentar o EIA/RIMA para o empreendimento Belo Monte e de ali estarem evidenciados todos os impactos ambientais bem como as ações para diminuir e compensar esses impactos, ela não apresenta adequadamente essas informações, apresentando somente algumas ações nos Relatórios Anual e Socioambiental, mas que não têm referência cruzada com as Demonstrações, ou seja, não foi possível identificar se esses compromissos, com características de passivo foram reconhecidos.

Esse estudo diferencia-se dos demais pois buscou analisar características da evidenciação de passivos ambientais nas empresas hidrelétricas assumidos na emissão de licenças ambientais.

\section{PROCEDIMENTOS METODOLÓGICOS}

A presente pesquisa classifica-se, quanto aos objetivos, como descritiva, pois têm como objetivo descrever características dos relatórios ambientais e contábeis de hidrelétricas, por meio de levantamentos e análises. Quanto a abordagem do problema é considerada qualitativa, pois, tem como propósito compreender com profundidade o fenômeno estudado - evidenciação de passivos ambientais -, a partir de interpretações e análise dos resultados.

Quanto aos meios, trata-se de uma pesquisa documental e bibliográfica. É documental, pois se utilizou dos Relatórios de Impacto Ambiental (RIMA), Estudos de Impacto Ambiental (EIA), Relatório de Sustentabilidade (RS), Notas Explicativas (NE) e

Prosppectus - Perspectivas Qualitativas em Contabilidade e Organizações. João Pessoa. v. 1, n. 1, p. 108 135, jul/2021. 
Aglaeudis Ferreira Rodrigues Campos; Christiano Coelho; Ana Lúcia de Araújo Lima Coelho; Maria Sueli Arnoud Fernandes.

Demonstrações Financeiras (DF). E é bibliográfica porque se utilizou de livros, artigos, revistas, jornais etc., para fundamentar o estudo.

A partir de cinco empresas geradoras de energia hidrelétrica, que fazem parte do Índice de Sustentabilidade Empresarial, listadas na B3 S.A. (Brasil, Bolsa, Balcão), foram feitas as coletas de dados para o estudo. Foram escolhidas essas empresas por possuírem usinas hidrelétricas (UHE), excluindo assim as demais empresas de energia que compõem o ISE. Na tabela 2 é possível observar as empresas geradoras de energia hidrelétrica pesquisadas:

Tabela 2

Empresas pesquisadas

\begin{tabular}{|l|c|}
\hline \multicolumn{1}{|c|}{ Empresas } & Quantidade de Usina Hidrelétrica \\
\hline AES Tietê Energia S.A. & 09 \\
\hline CIA Paranaense de Energia - COPEL & 17 \\
\hline Centrais Elet. Bras. S.A - ELETROBRAS & 48 \\
\hline Energias do Brasil S.A. & 03 \\
\hline Engie Brasil Energia S.A. & 12 \\
\hline
\end{tabular}

O período da publicação dos relatórios pesquisados foi de 2012 a 2019 e buscouse verificar as características de evidenciação dos passivos ambientais das empresas supracitadas. Foi analisado EIA/RIMA das empresas da amostra e verificado se os passivos ambientais listados nesses documentos foram divulgados nas Demonstrações Financeiras Padronizadas (DFP) dessas empresas - Balanço Patrimonial, Demonstração do Resultado do Exercício, Demonstração dos Resultados Abrangentes, Demonstração das Mutações do Patrimônio Líquido, Demonstração dos Fluxos de caixa, Demonstração do Valor Adicionado e Notas Explicativas. Além da análise das DFP, também foram analisados o Relatório de Sustentabilidade e o RIMA das usinas hidrelétricas das empresas deste estudo, disponíveis no site da B3, empresas e órgãos de licenciamento ambiental de cada estado que a empresa possui UHE.

Para a primeira etapa da coleta dos dados, foi utilizado o checklist 1 , que provém de uma adaptação dos estudos de Novis e Ferreira (2017), esta etapa consiste em buscar a partir do RIMA das UHE os passivos ambientais assumidos no licenciamento ambiental, através das variáveis nomeada como "grupo de ações ambientais", de acordo com a tabela 3: 
Aglaeudis Ferreira Rodrigues Campos; Christiano Coelho; Ana Lúcia de Araújo Lima Coelho; Maria Sueli Arnoud Fernandes.

Tabela 3

Categorias da pesquisa 1 (grupo de ações ambientais)

\begin{tabular}{|c|l|}
\hline Categorias & \multicolumn{1}{c|}{ Grupo de ação ambiental } \\
\hline 1 & Acompanhamento geológico/geotécnico e de recursos minerais \\
\hline 2 & Gestão de recursos hídricos \\
\hline 3 & Conservação dos ecossistemas terrestres \\
\hline 4 & Conservação dos ecossistemas aquáticos \\
\hline 5 & Saneamento básico para os municípios afetados pela UHE \\
\hline 6 & Educação ambiental \\
\hline 7 & Monitoramento ambiental \\
\hline 8 & Proposição de áreas de preservação permanente (APP) \\
\hline
\end{tabular}

Fonte: adaptado de Novis e Ferreira (2017).

Para a segunda etapa da coleta, foi utilizado o checklist 2, conforme a tabela 4, que teve como base as pesquisas de Carvalho (2012); Coelho (2010), em que contém cinco categorias distribuídas por meio de "classificações dos passivos ambientais".

Tabela 4

Categorias da pesquisa 1 (Passivos ambientais)

\begin{tabular}{|c|l|}
\hline Classificações & \multicolumn{1}{|c|}{ Comentários } \\
\hline Provisões Ambientais & $\begin{array}{l}\text { As provisões podem ser reconhecidas quando a empresa assume o } \\
\text { compromisso de reparar o dano ambiental causado pela atividade. Podem ser } \\
\text { reconhecidas após ocorrer o dano ambiental e quando forem estimados os } \\
\text { valores para realização das ações organizadas na reparação do meio ambiente. }\end{array}$ \\
\hline Degradação Ambiental & $\begin{array}{l}\text { Identificados nas ações organizadas para reparar a degradação ambiental do } \\
\text { solo, ar ou água. }\end{array}$ \\
\hline Monitoramento & $\begin{array}{l}\text { Considerados passivos ambientais operacionais que são reconhecidos quando } \\
\text { ocorrem o custo ou a despesa ambiental. Não são, portanto, provisionados. }\end{array}$ \\
\hline Indenizações & $\begin{array}{l}\text { As obrigações assumidas em ações organizadas referente a indenizações, } \\
\text { remanejamento ou monitoramento da população afetada. }\end{array}$ \\
\hline Contingências & $\begin{array}{l}\text { As ações organizadas referente a riscos ambientais. Independente de } \\
\text { mensuração foi considerado um passivo ambiental. Poderá ser evidenciado nas } \\
\text { Ambientais } \\
\text { forma qualitativa). }\end{array}$ \\
\hline
\end{tabular}

Fonte: adaptado de Coelho (2010); e Carvalho (2012).

Após a análise realizada nas DFP das empresas, foi criado um código, no qual um (1) evidencia algum grupo de ação conforme o checklist 1, e evidencia algumas das características supracitadas de passivos ambientais de acordo com o checklist 2; zero (0) não é evidenciado conforme o checklist 1 que trata dos grupos ações ambientais, e não evidencia algumas das características de passivos ambientais. Em sequência a esta análise foi observado a qualidade dessas informações conforme a tabela 5:

Prosppectus - Perspectivas Qualitativas em Contabilidade e Organizações. João Pessoa. v. 1, n. 1, p. 108 $135, \mathrm{jul} / 2021$. 
Aglaeudis Ferreira Rodrigues Campos; Christiano Coelho; Ana Lúcia de Araújo Lima Coelho; Maria Sueli Arnoud Fernandes.

Tabela 5

Categorias da pesquisa 1 (Informação evidenciada)

\begin{tabular}{|c|l|l|}
\hline Categorias & Qualidade & \multicolumn{1}{c|}{ Significado } \\
\hline IC & $\begin{array}{c}\text { Informação } \\
\text { Completa }\end{array}$ & $\begin{array}{l}\text { A informação prevista no checklist 1 e 2 encontra-se presente em um desses dados: } \\
\text { relatório da administração, relatório de sustentabilidade, demonstrações } \\
\text { financeiras e notas explicativas. }\end{array}$ \\
\hline II & $\begin{array}{c}\text { Informação } \\
\text { Incompleta }\end{array}$ & $\begin{array}{l}\text { A informação prevista no checklist 1 e 2 encontra-se incompleta em um desses } \\
\text { dados: relatório da administração, relatório de sustentabilidade, demonstrações } \\
\text { financeiras e notas explicativas. }\end{array}$ \\
\hline IA & $\begin{array}{c}\text { Anformação } \\
\text { Ausente }\end{array}$ & $\begin{array}{l}\text { A informação prevista no checklist 1 e 2 não se encontra no relatório da } \\
\text { administração, relatório de sustentabilidade, demonstrações financeiras e notas } \\
\text { explicativas. }\end{array}$ \\
\hline
\end{tabular}

Fonte: adaptado de Benetti et al. (2014, p.81).

Em relação as fontes de dados que foram utilizados nesta pesquisa, foi feita uma verificação prévia destas fontes a fim de verificar a acessibilidade dos dados, deste modo, foi verificado que o acesso a estes documentos é disponibilizado pelas empresas de amostra, site da B3 e órgãos de licenciamento ambiental, subsidiando a coleta. $\mathrm{Na}$ tabela a seguir é descrito as etapas da coleta dos dados deste estudo.

Tabela 6

Etapas para coleta dos dados

\begin{tabular}{|c|l|}
\hline Etapa & \multicolumn{1}{c|}{ O que deverá ser coletado? } \\
\hline 1 & $\begin{array}{l}\text { Buscar no RIMA das empresas de amostra os passivos ambientais assumidos no licenciamento } \\
\text { ambiental, através das variáveis de grupos de ações, conforme a tabela 3. }\end{array}$ \\
\hline 2 & $\begin{array}{l}\text { Investigar se as ações descritas no RIMA das empresas de amostra conforme o quadro 3 estão } \\
\text { sendo evidenciadas nas DFP ou no relatório de sustentabilidade. }\end{array}$ \\
\hline 3 & $\begin{array}{l}\text { Analisar nas empresas de amostra se as variáveis da tabela 4 estão sendo evidenciadas nas DFP } \\
\text { ou no relatório de sustentabilidade. }\end{array}$ \\
\hline 4 & $\begin{array}{l}\text { Inferir a qualidade das informações evidenciadas nas DFP ou no relatório de sustentabilidade } \\
\text { das empresas de acordo com a tabela 5. }\end{array}$ \\
\hline
\end{tabular}

A partir da coleta, os dados foram tratados no programa de planilhas eletrônicas Excel, e dos resultados extraídos deste software, foram feitas as análises e interpretações.

\section{APRESENTAÇÃO E ANÁLISE DOS RESULTADOS}

Os resultados evidenciados dependeram das informações que as empresas apresentaram em suas Demonstrações Financeiras Padronizadas e Relatório de sustentabilidade nos períodos de 2012 a 2019. Deste modo, buscou-se inicialmente identificar as empresas que evidenciaram os grupos de ações ambientais assumidos no licenciamento ambiental, conforme a tabela 6.

Prosppectus - Perspectivas Qualitativas em Contabilidade e Organizações. João Pessoa. v. 1, n. 1, p. 108 $135, \mathrm{jul} / 2021$. 
Aglaeudis Ferreira Rodrigues Campos; Christiano Coelho; Ana Lúcia de Araújo Lima Coelho; Maria Sueli Arnoud Fernandes.

Tabela 7

Evidenciação dos grupos de ação ambiental no período de 2012 a 2019

\begin{tabular}{|c|c|c|c|c|c|}
\hline \multirow{2}{*}{ Itens } & AES & COPEL & ELETROBRAS & ENERGIAS & ENGIE \\
\hline & ANOS & ANOS & ANOS & ANOS & ANOS \\
\hline $\begin{array}{l}\text { Acompanhamento geológico/geotécnico } \\
\text { e de recursos minerais }\end{array}$ & - & $\begin{array}{c}2017, \\
2018 \text { e } \\
2019\end{array}$ & - & - & - \\
\hline Gestão de recursos hídricos & $\begin{array}{l}2016 \text { e } \\
2017\end{array}$ & $\begin{array}{c}2012 \\
a \\
2019 \\
\end{array}$ & $\begin{array}{c}2012 \\
a \\
2019 \\
\end{array}$ & $\begin{array}{l}2016 \\
2017 \text { e }\end{array}$ & $\begin{array}{c}2016 \text { e } \\
2017\end{array}$ \\
\hline Conservação dos ecossistemas terrestres & $\begin{array}{c}2016 \\
a \\
2019 \\
\end{array}$ & $\begin{array}{c}2016 \\
a \\
2019 \\
\end{array}$ & - & 2017 & - \\
\hline Conservação dos ecossistemas aquáticos & $\begin{array}{c}2014, \\
2016 \text { a } 2019\end{array}$ & $\begin{array}{c}2016 \\
a \\
2019 \\
\end{array}$ & - & - & - \\
\hline $\begin{array}{l}\text { Saneamento básico para os municípios } \\
\text { afetados pela UHE }\end{array}$ & 2015 & $\begin{array}{c}2013 \text { e } \\
2014\end{array}$ & - & 2012 & - \\
\hline Educação ambiental & 2012 & - & $\begin{array}{c}2012 \mathrm{e} \\
2013 \\
\end{array}$ & 2012 & 2017 \\
\hline Monitoramento ambiental & $\begin{array}{c}2013, \\
2016 \text { a } 2018\end{array}$ & $\begin{array}{c}2012 \\
a \\
2019 \\
\end{array}$ & $\begin{array}{c}2014 \\
a \\
2019 \\
\end{array}$ & $\begin{array}{l}2012 \text { e } \\
2013\end{array}$ & - \\
\hline $\begin{array}{l}\text { Proposição de áreas de preservação } \\
\text { permanente (APP) }\end{array}$ & 2012 & $\begin{array}{c}2016 \\
a \\
2019 \\
\end{array}$ & - & - & - \\
\hline
\end{tabular}

$\mathrm{Na}$ tabela 7 pode-se visualizar que a categoria referente ao Acompanhamento Geológico/Geotécnico e de Recursos Minerais só é evidenciado a partir do ano de 2017 a 2019 por apenas uma empresa UHE a CIA Paranaense de Energia - COPEL. Os estudos de Novis e Ferreira (2017) enfatizam que no ano de 2012 a UHE Belo Monte, em suas notas explicativas, não evidenciou nenhuma informação socioambiental, portanto a categoria referente ao Acompanhamento Geológico/Geotécnico foi apresentada pela UHE, dessa forma os resultados encontrados nesse estudo se assemelham aos achados dos autores supramencionados.

Em relação a Gestão Recursos Hídricos, as empresas CIA Paranaense de Energia - COPEL e Centrais Elet. Bras. S.A. - ELETROBRAS foram as empresas que mais evidenciaram essa categoria de forma contínua, dos anos de 2012 a 2019. As demais empresas só fizeram a evidenciação de como está sendo feita a Gestão de Recursos Hídricos em suas UHE a partir do ano de 2016 a 2019.

As empresas AES Tietê Energia S.A. e CIA Paranaense de Energia - COPEL, foram as companhias que mais evidenciaram a Conservação dos Ecossistemas Terrestres, nos anos de 2016 a 2019. No ano de 2017 nas DFP da empresa Energias do 
Aglaeudis Ferreira Rodrigues Campos; Christiano Coelho; Ana Lúcia de Araújo Lima Coelho; Maria Sueli Arnoud Fernandes.

Brasil S.A., foi evidenciado aspectos relacionados a Conservação dos Ecossistemas Terrestres. Segundo o Ministério do Meio Ambiente (2017) a conservação dos ecossistemas terrestres se encontra no Objetivo de Desenvolvimento Sustentável (ODS) número 15, que trata da proteção e recuperação do uso sustentável dos ecossistemas terrestres, gerindo de forma sustentável as florestas, combatendo a desertificação, a degradação da terra e a biodiversidade. Ademais, as empresas Eletrobras e Engie Brasil Energia S.A. não evidenciaram a categoria referente a Conservação dos Ecossistemas Terrestres em suas DFP e nem em seus Relatórios de Sustentabilidade.

Em se tratando da categoria alusivo a Conservação dos Ecossistemas Aquáticos, é possível verificar na tabela 6 que nos anos de 2012, 2013 e 2015 não houve evidenciação por nenhuma empresa de UHE que compõe esse estudo. Porém a companhia que mais fez a divulgação dessa categoria em seus relatórios foi a AES Tietê Energia S.A., no ano de 2014 e nos anos de 2016 a 2019. Em seguida, a empresa COPEL que evidenciou essa categoria nos anos de 2016 a 2019 em suas DFP e Relatórios de Sustentabilidade.

Concernente ao item Saneamento Básico para os Municípios Afetados pela UHE, foi evidenciada por três empresas, mas não de forma regular, com exceção da Copel que divulgou essa categoria nos anos 2013 e 2014. Essa categoria foi evidenciada uma única vez no ano de 2012 pela empresa Energias do Brasil S.A., e em 2015 pela Companhia AES Tietê Energia S.A. De acordo com Oliveira (2004), o impacto ambiental que a construção de uma UHE traz é bastante intenso pois, onde é recebido o grande lago que serve de reservatório da hidrelétrica existem diversas modificações, como a mudança do clima, espécies de peixes desaparecidos, animais que fogem para refúgios secos e etc., além do impacto social, onde de acordo com os resultados do estudo do autor supracitado, cerca de 33 mil pessoas deixaram suas casas, tendo que recomeçar sua vida do zero em um outro lugar.

No ano de 2012 as empresas AES Tietê, Eletrobras e Energias do Brasil divulgaram em seus relatórios financeiros investimentos relativos à Educação Ambiental, porém no ano subsequente (2013) apenas uma empresa (Eletrobras) continuou evidenciando essa categoria. Em 2017, a Engie Brasil Energia S.A., evidenciou nas DFP conforme as condicionantes descritas no RIMA das suas hidrelétricas. Também é possível observar que não houve continuidade das evidenciações desses investimentos referente a Educação Ambiental. Desta forma, também não possui nenhuma Nota Explicativa que explique o motivo da não continuidade ou a interrupção do investimento em Educação Ambiental. A CIA Paranaense de Energia - COPEL, não evidenciou nada referente a Educação Ambiental em seus relatórios financeiros no período de 2012 a 2019.

Costa (2018) constatou que as empresas de mineração em 2016 e 2017 não evidenciaram de maneira satisfatória o item relacionado a Educação Ambiental em seus relatórios. Por outro lado, Costa, Lima e Alves (2020) inferem que as empresas nos setores de madeira, papel e celulose estão evidenciando de forma positiva sua interação com o meio ambiente através de projetos ambientais e educação ambiental. 
Aglaeudis Ferreira Rodrigues Campos; Christiano Coelho; Ana Lúcia de Araújo Lima Coelho; Maria Sueli Arnoud Fernandes.

A empresa que mais evidenciou a categoria Monitoramento Ambiental foi a Copel que manteve divulgando nos anos de 2012 a 2019. Em sequência, a empresa Eletrobras que divulgou, em seus relatórios, nos anos de 2014 a 2019 como estava sendo o Monitoramento Ambiental das suas UHE. Já a empresa AES Tietê evidenciou essa categoria nos anos 2013 e nos anos de 2016 a 2018 e a empresa Energias do Brasil, nos anos 2012 e 2013. Em contrapartida, a empresa Engie Brasil não fez nenhuma publicação referente ao Monitoramento Ambiental em seus relatórios financeiros e de sustentabilidade. O Monitoramento Ambiental é um processo de coleta de dados, estudo e acompanhamento contínuo e sistemático das variáveis ambientais, o objetivo desse processo é identificar e avaliar de forma qualitativa e quantitativa, as condições dos recursos naturais, e as tendências ao longo do tempo (Ramos \& Luchiari Junior, 2020).

Por fim, a categoria referente a Proposição de Áreas de Preservação Permanente (APP) foi evidenciada por duas empresas: a AES Tietê no ano de 2012 e a COPEL nos anos de 2016 a 2019. De acordo com a Lei Federal n‥ 12.651/2012, a função da APP é preservar os recursos hídricos, a paisagem, a estabilidade geológica e a biodiversidade, facilitando o fluxo gênico de fauna e flora, assim como a proteção do solo, assegurando o bem-estar da sociedade.

Na tabela a seguir será demonstrado as empresas de energia hidrelétrica que evidenciaram os passivos ambientais em seus relatórios de sustentabilidade e financeiro no período de 2012 a 2019.

Tabela 8

Evidenciação dos passivos ambientais no período de 2012 a 2019

\begin{tabular}{|c|c|c|c|c|c|}
\hline \multirow{2}{*}{ Itens } & AES & COPEL & ELETROBRAS & ENERGIAS & ENGIE \\
\hline & ANOS & ANOS & ANOS & ANOS & ANOS \\
\hline Provisões Ambientais & $\begin{array}{c}2012 \\
a \\
2019\end{array}$ & $\begin{array}{c}2012 \text { a } 2014 \\
\text { e } \\
2016 \text { a } 2019\end{array}$ & $\begin{array}{c}2012 \\
\text { a } \\
2019\end{array}$ & $\begin{array}{c}2012 \\
a \\
2019\end{array}$ & $\begin{array}{c}2012 \\
a \\
2019\end{array}$ \\
\hline Degradação Ambiental & $\begin{array}{c}2013 \\
a \\
2019\end{array}$ & $\begin{array}{c}2012 \mathrm{e} \\
2013\end{array}$ & - & - & 2014 \\
\hline Monitoramento & $\begin{array}{c}2012 \text { a } 2013, \\
2016 \text { e } \\
2019\end{array}$ & 2014 & $\begin{array}{c}2012 \\
a \\
2019\end{array}$ & $\begin{array}{c}2013 \\
2018 \text { a } 2019\end{array}$ & - \\
\hline $\begin{array}{c}\text { Indenizações Ambientais a } \\
\text { Pagar }\end{array}$ & $\begin{array}{c}2012, \\
2015 \text { a } 2019\end{array}$ & $\begin{array}{c}2013 \text { e } 2014 \\
2016\end{array}$ & $\begin{array}{c}2012 \\
a \\
2019\end{array}$ & $\begin{array}{c}2014 \mathrm{e} \\
2018\end{array}$ & $\begin{array}{c}2016 \\
a \\
2019\end{array}$ \\
\hline Contingências Ambientais & $\begin{array}{c}2013 \\
2016 \text { a } 2019\end{array}$ & - & $\begin{array}{c}2012 \\
a \\
2019\end{array}$ & $\begin{array}{l}2013 \text { a } 2014 \\
2018 \text { a } 2019\end{array}$ & $\begin{array}{c}2016 \\
a \\
2019\end{array}$ \\
\hline
\end{tabular}

É perceptível verificar que o item referente a Provisões Ambientais é evidenciado por cinco empresas que compõe essa pesquisa nos anos de 2012 a 2019, com a exceção da Copel S.A., que não divulgou no ano de 2015. Estes resultados concordam com a

Prosppectus - Perspectivas Qualitativas em Contabilidade e Organizações. João Pessoa. v. 1, n. 1, p. 108 135, jul/2021. 
Aglaeudis Ferreira Rodrigues Campos; Christiano Coelho; Ana Lúcia de Araújo Lima Coelho; Maria Sueli Arnoud Fernandes.

pesquisa de Marques, Arruda e Mattos (2016) que investigou se as empresas ganhadoras do prêmio transparência da ANEFAC/FIPECAFI/SERASA no ano de 2015 estavam identificando ou reconhecendo passivos ambientais. Os resultados desse estudo demostraram que $100 \%$ das empresas ganhadoras desse prêmio apresentaram algum tipo de informação referente a dano ambiental em seus relatórios. Desse modo, Almeida e Batista (2016) discorrem que antes do Pronunciamento Técnico CPC 25 (2009) apenas $7 \%$ das empresas altamente poluidoras com ações negociadas na B3 S.A. evidenciavam informações sobre provisões e passivos ambientais.

A Degradação Ambiental é divulgada com uma maior frequência pela empresa AES Tietê nos anos de 2013 a 2019, em seguida pela Copel S.A., no período anual de 2012 e 2013 e pela Engie Brasil S.A., no ano de 2014, onde em seus relatórios financeiros torna público as ações de reparação ambiental do solo e água causados por suas UHE ademais não foi encontrado nenhuma mitigação em relação ao ar por essa empresa.

Nas DFP da Copel, foram encontrados projetos de mitigação dos impactos da construção do empreendimento da UHE Colíder, que receberam investimento de $R \$$ 6,8 milhões e $\mathrm{R} \$ 8$ milhões na gestão ambiental dos empreendimentos em operação. De acordo com Rover Borba e Borget (2008), esse tipo de investimento tem a finalidade de obter o retorno de boas práticas ambientais, tendo como meta a recuperação de matas ciliares, áreas de preservação permanente e gerenciamento de resíduos.

Já nos relatórios financeiros da Engie Brasil S.A., foi encontrado um investimento de aproximadamente 4 milhões de reais para a preservação e/ ou recuperação de ambientes degradados. Vale salientar que as empresas Eletrobras e Energias do Brasil não evidenciaram esse item em seus relatórios.

O item referente ao Monitoramento é relativo a passivos ambientais operacionais que são reconhecidos quando ocorrem o custo ou a despesa ambiental. Não são, portanto, provisionados. A empresa Eletrobras divulgou de forma contínua (2012 a 2019) em seus relatórios o monitoramento de passivos ambientais operacionais sendo assim a empresa que mais divulgou esse item, que em 2016 foi evidenciado no relatório de sustentabilidade e DFP custos diretos com gerência de Meio Ambiente no valor de R\$ 7.279,000,00. Em sequência a empresa AES Tietê no período de 2012 a 2013 e 2016 a 2019 evidenciou em seus relatórios os custos e ou despesas ambientais. No período de 2013 consta no relatório de sustentabilidade da AES Tietê, gastos em proteção ambiental e gestão ambiental no valor de R $\$ 111.004,000,00$.

Em 2014, além das empresas supracitadas a Copel S.A., também evidenciou nas DFP e relatório de sustentabilidade o item referente a monitoramento, neste mesmo ano teve um recurso aplicado em P\&D ao meio ambiente de $\mathrm{R} \$ 709.133,79$. A Energias do Brasil S.A., evidenciou em seus relatórios nos anos 2013 e 2018 a 2019 despesas ambientais, em 2018 teve uma despesa ambiental no valor de R\$19.916,000,00, considerada a maior nestes 3 anos de evidenciação.

No que se refere a Indenizações Ambientais a Pagar a Eletrobras S.A., teve um maior destaque, evidenciando de forma presente este item no período de 2012 a $2019 \mathrm{em}$ 
Aglaeudis Ferreira Rodrigues Campos; Christiano Coelho; Ana Lúcia de Araújo Lima Coelho; Maria Sueli Arnoud Fernandes.

seus relatórios. Já a empresa AES Tietê S.A., no ano de 2014 evidenciou 340 processos de ações públicas sobre supostos danos ambientais, um dos processos são referentes a ocupações irregulares em áreas de preservação permanente, com valor provisionado de $\mathrm{R} \$ 1.722 .000,00$, a empresa também teve processos referentes a danos ambientais nos anos de 2015 a 2019. Foi encontrado no relatório de sustentabilidade no ano de 2015 da Empresa Energia do Brasil S.A., multas e indenizações ambientais a pagar no valor de $\mathrm{R} \$ 846.381,000,00$.

A empresa Eletrobras vem evidenciando no período de 2012 a 2019 as Contingências Ambientais tanto nas demonstrações contábeis, quanto nas notas explicativas. Estes resultados se opõem aos estudos de Barbosa, Araújo, Alves e Campos (2014) que identificaram que as empresas de papel e celulose divulgam de forma parcial essas informações, apresentando apenas os ativos ambientais e deixam de informar os passivos ambientais.

A Engie Brasil S.A., divulga os contingentes ambientais nas DFP a partir do ano de 2016 a 2019; já a única empresa que não evidenciou em seus relatórios o item alusivo a Contingências Ambientais foi a empresa Copel S.A. Isto posto, Suave, Codesso, Moraes, Vicente e Lunkes (2013) fez um levantamento com as empresas listadas na B3, afim de verificar se elas atendiam ao que preceitua o Pronunciamento Técnico CPC 25 (2009), em relação a passivos contingentes, os autores identificaram que as empresas priorizam a divulgação de passivos contingentes concernentes a causas trabalhistas, cíveis e fiscais, de modo que os dados apresentados sobre o meio ambiente são considerados irrelevantes.

Na tabela a seguir é demonstrado a pontuação em relação à qualidade da informação referente aos itens supracitados, de acordo com as tabelas 7 e 8, das empresas de energia hidrelétrica que fazem parte do ISE, listadas na B3.

Tabela 9

Qualidade das informações verificadas na pesquisa

\begin{tabular}{|l|c|c|}
\hline Empresa & $\begin{array}{c}\text { Evidenciação } \\
\text { Ações } \\
\text { Ambientais } \\
\text { (Checklist 1) }\end{array}$ & $\begin{array}{c}\text { Evidenciação } \\
\text { Passivo Ambiental } \\
\text { (Checklist 2) }\end{array}$ \\
\hline AES Tietê Energia S.A. & Informação Incompleta & Informação Incompleta \\
\hline CIA Paranaense de Energia - COPEL & Informação Incompleta & Informação Incompleta \\
\hline Centrais Elet. Bras. S.A - ELETROBRAS & Informação Incompleta & Informação Incompleta \\
\hline Energias do Brasil S.A. & Informação Incompleta & Informação Incompleta \\
\hline Engie Brasil Energia S.A. & Informação Incompleta & Informação Incompleta \\
\hline
\end{tabular}

Observa-se que todas as empresas apresentaram de forma incompleta as informações de acordo com o checklist 1 e 2 . Portanto, vale salientar que a empresa Eletrobras só recebeu informação incompleta no checklist 2, porque não evidenciou o item referente a degradação ambiental em seus relatórios, deste modo é possível mencionar que foi a empresa que mais evidenciou os itens do checklist 2 com 32 
Aglaeudis Ferreira Rodrigues Campos; Christiano Coelho; Ana Lúcia de Araújo Lima Coelho; Maria Sueli Arnoud Fernandes.

divulgações. Já a empresa que mais divulgou os itens do checklist 1 foi a Copel com 31 evidenciações.

Outrossim, pode-se concluir que há necessidade das empresas melhorarem as evidenciações acerca das informações ambientais reforçando o que se apresenta em outros estudos (Por exemplo, Barbosa et al., 2014; Barcelos et al., 2016; Coelho et al., 2010; Negash \& Lemma, 2020; Paananen et al., 2021; Rover et al., 2008; Senn \& GiordanoSpring, 2020). Vale salientar que o arcabouço teórico e legal existente para a realidade brasileira está aderente às normas internacionais. Nesse sentido, também se destaca, como achado deste estudo, a fragilidade de textos normativos que estão facultando a evidenciação de passivos ambientais em relatórios contábeis e suas respectivas notas explicativas (Senn \& Giordano-Spring, 2020).

\section{CONSIDERAÇÕES FINAIS}

Este estudo teve como objetivo analisar características da evidenciação dos passivos ambientais de empresas hidrelétricas assumidos na emissão de licenças ambientais. A partir da análise dos resultados, constatou-se que de acordo com o checklist 1 referente aos grupos de ações ambientais, os itens que foram divulgadas de forma mais representativa nos relatórios das empresas de energia hidrelétrica no período de 2012 a 2019 foram os itens que tratam da Gestão de Recursos Hídricos, Educação Ambiental e Monitoramento Ambiental. Por outro lado, a variável que menos foi evidenciada foi concernente ao Acompanhamento Geológico/Geotécnico e de Recursos Minerais.

Em relação ao checklist 2 (Passivos Ambientais), os itens que mais foram evidenciados pelas empresas foram as Provisões Ambientais, as Indenizações Ambientais e as Contingências Ambientais. Contudo, o item Degradação Ambiental foi o menos evidenciado nos relatórios das empresas que compõe este estudo.

No que se refere a qualidade das informações apresentadas pelas empresas em suas Demonstrações Financeiras Padronizadas e Relatórios de Sustentabilidade, percebe-se que todas as empresas que compõe o estudo apresentaram informações incompletas em relação a evidenciação dos grupos de ações ambientais, das empresas advindas a partir do licenciamento ambiental, e a divulgação dos passivos ambientais.

Por meio dos resultados encontrados neste estudo, nota-se a necessidade e a importância da evidenciação das práticas ambientais nos relatórios financeiros e de sustentabilidade das empresas, sendo imprescindível a transparência por parte das empresas de usinas hidrelétricas.

Os resultados desta pesquisa provocam algumas reflexões. Numa perspectiva teórica, verifica-se que a Contabilidade precisa avançar para debater e estabelecer critérios que favoreçam o aumento da evidenciação de informações ambientais a partir do registro das mutações patrimoniais. Este estudo revela que empresas no Brasil apresentam um nível baixo de evidenciação relacionado a passivos ambientais assemelhando-se a outros países. Nesse sentido, aponta-se para a necessidade de 
Aglaeudis Ferreira Rodrigues Campos; Christiano Coelho; Ana Lúcia de Araújo Lima Coelho; Maria Sueli Arnoud Fernandes.

direcionar esforços teóricos sobre o aumento das exigências normativas, principalmente no que tange a Normas Internacionais de Contabilidade.

Em termos práticos, o mundo passa por transformações ambientais que requerem maior intervenção das nações quando estabelecem acordos relacionados a um desenvolvimento sustentável. A legislação ambiental e seus instrumentos de controle, por sua vez, pode aumentar o nível de evidenciação dos passivos ambientais assumidos e realizados pelas empresas. Assim, os órgãos ambientais responsáveis pela fiscalização e controle das práticas ambientais podem entender a Contabilidade como um instrumento de informação útil para seu processo decisório em favor daquele desenvolvimento.

Uma das dificuldades encontradas neste trabalho se deu pela escassez da literatura sobre a temática e a ausência de detalhamento das informações por parte de algumas empresas (Engie Brasil Energia S.A., Centrais Elet. Bras. S.A - ELETROBRAS e Energias do Brasil S.A.). Nessa perspectiva, fica o incentivo à realização de trabalhos futuros, em analisar não apenas as empresas de energia hidrelétrica que fazem parte do ISE, mas todas que são listadas nesse segmento na B3, a fim de fazer uma comparação e verificar as implicações econômico-financeiro das empresas que evidenciaram os passivos ambientais assumidos no licenciamento ambiental. Esta pesquisa também contribui como um auxílio na tomada de decisão dos usuários das informações contábeis, especialmente aos stakeholders.

\section{REFERÊNCIAS}

Almeida, K. K. N., Batista, F. F. (2016). Provisões Contingentes Ambientais e seus Reflexos no Endividamento das empresas de alto impacto ambiental após adoção do CPC 25. Sociedade, Contabilidade e Gestão, 11(1). https://doi.org/10.21446/scg ufrj.v11i1.13372.

Baral, N., Pokharel, M. P. (2017). How sustainability is reflected in the S\&P 500 companies' strategic documents. Organization E Environment, 30(2), 122-141. https://doi.org/10.1177/1086026616645381.

Barbieri, J. C. (2011). Gestão ambiental empresarial: Conceitos, Modelos e Instrumentos. 3. ed. Saraiva.

Barbieri, J. C. (2017) Gestão ambiental empresarial. 1. ed. Saraiva.

Barbosa, E. S., Araújo, S. R. P., Alves, O. Á. T., \& Campos, R. I. C. (2014). Evidenciação das informações ambientais segundo a NBC T-15: um estudo nas empresas do setor de papel e celulose de 2006 a 2010. Revista de Administração, Contabilidade e Sustentabilidade, 4(1). DOI:10.18696/reunir.v4i1.108.

Barcelos, D. P., Tassigny, M. M., de Oliveira, C. M. G., de Almeida, B. F. P. \& Frota, A. J. A. (2016). Evidenciação ambiental à luz da NBC T-15: o caso da natura. Amazônia, Organizações e Sustentabilidade, 4(2), 127-146. http://dx.doi.org/10.17800/aos.v4i2.312.

Prosppectus - Perspectivas Qualitativas em Contabilidade e Organizações. João Pessoa. v. 1, n. 1, p. 108 135, jul/2021. 
Aglaeudis Ferreira Rodrigues Campos; Christiano Coelho; Ana Lúcia de Araújo Lima Coelho; Maria Sueli Arnoud Fernandes.

Berthelot, S., Cormier, D., Magnan, M. (2003). Environmental, disclosure, research: review and synthesis. Journal of accounting literature, 22(1), 1-44.

Benetti, K., Benneti, K., Braun, M., Oro, I. M., \& Utzig, M. J. S. (2014). Evidenciação de Subvenção e Assistência Governamentais das Empresas na BM \& FBOVESPA. Revista Evidenciação Contábil \& Finanças, 2(1), 75-90. DOI: 10.18405/recfin20140105.

Beuren, I, M., Hein, N., Boff, M. L. (2011). Estratégias de legitimidade organizacional de Lindblom versus geração familiar gestora de empresas familiares. Revista Iberoamericano de Contabilidad de Gestión, 9(17), 56-72.

Bim, E. F. (2016). Licenciamento Ambiental. 3. ed. Lumens Juris.

Carvalho, M, B, G. (2012). Contabilidade ambiental teórica e prática. 2. ed. Editora Juruá.

Coelho, C. (2010). Passivos ambientais com base nos relatórios de impacto ambiental: um estudo das atividades de energia hidrelétrica de Santa Catarina. [Dissertação de mestrado, Universidade Federal de Santa Catarina]. Biblioteca Digital de Teses e Dissertações da Universidade Federal de Santa Catarina. https://repositorio.ufsc.br/handle/123456789/94283

Coelho, C. (2019). Proposta de metodologia qualitativa para deliberação colegiada de licenças ambientais no Estado da Paraíba. [Tese de doutorado, Universidade Federal da Paraíba]. Biblioteca Digital de Teses e Dissertações da Universidade Federal da Paraíba. https://rei.biblioteca.ufpb.br/jspui/handle/123456789/20181

Coelho, C., Coelho, A. L. A. L., Dorow, A. (2010). Passivos ambientais com base nos relatórios de impacto ambiental: um estudo das atividades de energia hidrelétrica de Santa Catarina. Anais do encontro da associação nacional de pós-graduação e pesquisa em administração - EnANPAD. USP.

Conselho Nacional do Meio Ambiente CONAMA (2020). Resolução n 001, de 23 de janeiro de 1986, publicado no DOU de 17.02.86. Recuperado em 18 de junho de 2020 em www.mma.gov.br/por/conama/res/res/86/res0186.html.

Correa, J. C. Gonçalves, M. N., Moraes, R. O. (2015). Disclosure ambiental das companhias do setor de petróleo, gás e biocombustíveis listadas na BM\&FBOVESPA: uma análise a luz da teoria da legitimidade. Revista de Gestão Ambiental e Sustentabilidade, 4(3), 139-154.

Costa Filho, B. A., Rosa, F. (2017). Maturidade em gestão ambiental: revistando as melhorias práticas. Revista Eletrônica de administração, 23(2), 110-134. https://doi.org/10.1590/1413.2311.030.59633.

Costa, L. B. A. (2018). Contabilidade Ambiental na Evidenciação de Informações Socioambientais no Setor de Mineração de Companhias Abertas Listadas na BM\&FBOVESPA. Anais do encontro de gestão e negócios. PUC Minas.

Costa, L. B., Lima, F. A., Alves, P. M. (2020). Nível de evidenciação de informações socioambientais em empresas listadas na b3 nos setores de madeira, papel e celulose. RAGC, 8(36).

Prosppectus - Perspectivas Qualitativas em Contabilidade e Organizações. João Pessoa. v. 1, n. 1, p. 108 135, jul/2021. 
Aglaeudis Ferreira Rodrigues Campos; Christiano Coelho; Ana Lúcia de Araújo Lima Coelho; Maria Sueli Arnoud Fernandes.

Eckert, A., Corci Neto, S. L. H., Boff, D. S. (2015). Iniciativas e Práticas Ambientais das Pequenas e Médias Empresas do Vale do Caí - RS. Revista de Gestão Ambiental e Sustentabilidade, 4(1), 108-123.

Farias, T. (2017). Licenciamento ambiental: aspectos teóricos e práticos. 6. ed. Fórum.

Fernandes, S. M., Santiago, W. P., Peixoto, F. M. (2012). Passivo ambiental: um levantamento em empresas localizadas no município de Montes Claros/MG. Anais dos seminários em administração, Montes Claros.

Ferreira, A. C. S. (2011). Contabilidade Ambiental: Uma Informação para o Desenvolvimento Sustentável. 3. ed. Atlas.

Iudícibus, S., Martins, E., Gelbcke, E. R. (2010). Manual de Contabilidade Societária: Aplicável a Todas as Sociedades de Acordo com as Normas Internacionais e do CPC. 1. ed. Atlas.

Kasim, M. T. (2017). Evaluating the effectiveness of an environmental disclosure policy: An application to new South Wales. Resource and Energy Economics, 49(1), 113-131. https://doi.org/10.1016/j.reseneeco.2017.04.003.

Kraemer, M. E. P. (2011). Contabilidade ambiental como sistema de informações. Revista Brasileira de Contabilidade, 133(1), 68-83.

Lei no..12.651, de 25 de maio de 2012. (2012). Institui o Novo Código Florestal Brasileiro. Recuperado em 08 de outubro de 2020 em https://tinyurl.com/y5uvh82k

Lemos, P. I. L. (2008). Meio Ambiente e Responsabilidade civil do Proprietário: Análise do Nexo Causal. 1. ed. Revista dos tribunais

Li, Y., Richardson, G. D., Thornton, D. B. (1997). Corporate disclosure of environmental liability information: Theory and evidence. Contemporary Accouting Research, 14(3), 435-474. https://doi.org/10.1111/j.1911-3846.1997.tb00535.x.

Lima Filho, R. N. Bruni, A. L. Gomes, S. M. S. (2013). A compreensão dos estudantes sobre o conceito de passivo ambiental: um estudo nos cursos Ciências Contábeis em Salvador-BA. Revista Pensamento Contemporâneo em Administração, 7(1), 108-121. https://doi.org/10.12712/rpca.v7i1.170.

Lu, Y., Abeysekera, I. (2017). What do stakeholders care about? Investigating corporate social and environmental disclosure in China. Journal of Business Ethics, 144(1), 169184. DOI: 10.1007/s10551-015-2844-5.

Madruga Filho, V. J. P. (2019). A participação popular no procedimento de licenciamento ambiental na Paraíba. [Dissertação de mestrado, Universidade Federal da Paraíba]. Biblioteca Digital de Teses e Dissertações da Universidade Federal da Paraíba. https://repositorio.ufpb.br/jspui/handle/123456789/16757.

Marques, A. L. (2016). Reconhecimento contábil de passivos ambientais: um estudo de caso sobre a aplicação de metodologias de valoração econômica. [Tese de doutorado, Universidade Federal do Rio de Janeiro]. Biblioteca Digital de Teses e Dissertações da Universidade Federal da

Prosppectus - Perspectivas Qualitativas em Contabilidade e Organizações. João Pessoa. v. 1, n. 1, p. 108 $135, \mathrm{jul} / 2021$. 
Aglaeudis Ferreira Rodrigues Campos; Christiano Coelho; Ana Lúcia de Araújo Lima Coelho; Maria Sueli Arnoud Fernandes.

Paraíba.http://www.ie.ufrj.br/images/posgraducao/pped/dissertacoes_e_teses/Aless a ndra_de_Lima_Marques.pdf.

Marques, L. O., Arruda, L. L., Mattos, M. A. (2016). Passivo Ambiental: Uma Reflexão para a Contabilidade. Anais do congresso brasileiro de custos, Porto de Galinhas.

Marquezan, L. H. F., Seibert, R. M., Bartz, D., Barbosa, M. A. G., \& Alves, T. W. (2015). Análise dos determinantes do disclosure verde em relatórios anuais de empresas listadas na BM\&FBovespa. Contabilidade, Gestão e Governança, 18(1), 127-150.

Melo, L. C. A., Tinoco, J. E. P., Fernandes, M. F. (2010). Passivo Ambiental: a importância do reconhecimento, do registro contábil e da divulgação. Revista Eletrônica de Gestão de Negócios da Universidade Católica de Santos. Santos, 6(2), 72-101.

Negash M. \& Lemma T.T. (2020). Institutional pressures and the accounting and reporting of environmental liabilities. Business Strategy and the Environment, 29(5), 1941-1960. https://doi.org/10.1002/bse.2480.

Novis, P. L., Ferreira, A. C. de S. (2017). O relatório de Impacto Ambiental e a evidenciação de passivos ambientais: um estudo da UHE de Belo Monte. Anais do congresso de administração, sociedade e inovação, Petrópolis.

Oliveira, A. M. A. (2004). Qual o impacto ambiental da instalação de uma hidrelétrica? Recuperado em 06 de outubro de 2020, de https://tinyurl.com/y2d776ra.

Paananen M., Runesson E. \& Samani N. (2021). Time to clean up environmental liabilities reporting: disclosures, media exposure and market implications. Accounting Forum, 45(1), 85-116. https://doi.org/10.1080/01559982.2021.1872909.

Paiva, P. R. (2006). Contabilidade ambiental: evidenciação dos gastos ambientais com transparência e focada na prevenção. Atlas.

Ramos, N. P., Luchiari Junior, A. (2020). Monitoramento Ambiental. Agência Embrapa de Informação Tecnológica. Recuperado em 08 de outubro de 2020 em https://tinyurl.com/yyl9nzo8.

Ribeiro, M. S. (2010). Contabilidade Ambiental. 2. ed. Editora Saraiva.

Rover, S., Borba, J. A., Borget, A. (2008). Como as Empresas Classificadas no Índice de Sustentabilidade Empresarial (ISE) Evidenciam os Custos e Investimentos Ambientais? Revista de Custos e Agronegócio online, 4(1).

Sabino, B. L., Ferreira, S. J., Ferreira, M. D. D. (2020). Disclosure ambiental: As características das empresas influenciam na publicação dos relatórios de sustentabilidade? Anais do congresso USP de iniciação cientifica em contabilidade, São Paulo.

Sánchez, L. E. (2015). Avaliação de impacto ambiental. Oficina de Textos.

Santos, S. L. M., Braga, E. C., Cavalcante, P. R. N. (2019). Isomorfismo na Adoção de Práticas Ambientais: Um Estudo com as Empresas de Alto Potencial Poluidor Listadas na B3 SA. Anais do Congresso Brasileiro de Custos, Curitiba.

Prosppectus - Perspectivas Qualitativas em Contabilidade e Organizações. João Pessoa. v. 1, n. 1, p. 108 135, jul/2021. 
Aglaeudis Ferreira Rodrigues Campos; Christiano Coelho; Ana Lúcia de Araújo Lima Coelho; Maria Sueli Arnoud Fernandes.

Santos, A. D. O., Silva, F. B. D., Souza, S. D., \& Sousa, M. F. R. D. (2001). Contabilidade ambiental: Um estudo sobre sua aplicabilidade em empresas brasileiras. Revista Contabilidade $\mathcal{E}$ Finanças, 12(11), 89-99. Seiffert, M. E. B. (2010). Gestão ambiental: Instrumentos, esferas de ação e educação ambiental. 1. ed. Atlas

Senn J. \& Giordano-Spring S. (2020). The limits of environmental accounting disclosure: enforcement of regulations, standards and interpretative strategies. Accounting, Auditing and Accountability Journal, 33(6), 1367-1393. https://doi.org/10.1108/AAAJ04-2018-3461.

Shigunov, N. A.; Campos, L.M.S.; Shigunov, T. (2009). Fundamentos da Gestão Ambiental. Ciência Moderna.

Suave, R., Codesso, M. M., de Moraes P. H., Vicente, E. F. R., \& Lunkes, R. J. (2013). Divulgação de Passivos Contingentes nas empresas mais líquidas da BM\&FBovespa. Revista da UNIFEBE, 1(11).

Tinoco, J. E. P., Kraemer, M. E. P. (2011). Contabilidade e gestão ambiental. Atlas.

Vellani, C. L. (2008). Passivo ambiental e ecoeficiência. Revista FACEF Pesquisa, 11(3).

Xie, X. M., Zang, Z. P., \& Qi, G. Y. (2016). Assessing the environmental management efficiency of manufacturing sectors: evidence from emerging economies. Journal of Cleaner Production, 112, 1422-1431. https://doi.org/10.1016/j.jclepro.2015.08.006.

Prosppectus - Perspectivas Qualitativas em Contabilidade e Organizações. João Pessoa. v. 1, n. 1, p. 108 $135, \mathrm{jul} / 2021$. 
Aglaeudis Ferreira Rodrigues Campos; Christiano Coelho; Ana Lúcia de Araújo Lima Coelho; Maria Sueli Arnoud Fernandes.

\section{NOTAS}

\section{Contribuição de Autoria}

\begin{tabular}{|l|l|l|l|l|}
\hline Contribuição & $\begin{array}{c}\text { Aglaeudis } \\
\text { Ferreira } \\
\text { Rodrigues } \\
\text { Campos }\end{array}$ & $\begin{array}{c}\text { Christiano } \\
\text { Coelho }\end{array}$ & $\begin{array}{c}\text { Ana } \\
\text { Lúcia de } \\
\text { Araújo } \\
\text { Lima } \\
\text { Coelho }\end{array}$ & $\begin{array}{c}\text { Maria Sueli } \\
\text { Arnoud } \\
\text { Fernandes }\end{array}$ \\
\hline 1. Definição do problema de pesquisa & $\mathrm{X}$ & $\mathrm{X}$ & & \\
\hline 2. Fundamentação Teórica/Revisão de Literatura & $\mathrm{X}$ & $\mathrm{X}$ & $\mathrm{X}$ & \\
\hline 3. Definição dos procedimentos metodológicos & $\mathrm{X}$ & $\mathrm{X}$ & & \\
\hline 4. Coleta de dados & $\mathrm{X}$ & & & \\
\hline 5. Análise e interpretação dos dados & $\mathrm{X}$ & $\mathrm{X}$ & & $\mathrm{X}$ \\
\hline 6. Revisão crítica do artigo & $\mathrm{X}$ & $\mathrm{X}$ & $\mathrm{X}$ & $\mathrm{X}$ \\
\hline 7. Escrita do artigo & $\mathrm{X}$ & $\mathrm{X}$ & $\mathrm{X}$ & \\
\hline 8. Outros (especificar) & & & & \\
\hline
\end{tabular}

\section{Editores}

Editora Geral: Viviane da Costa Freitag

Editora Adjunta: Karla Katiuscia Nóbrega de Almeida

\section{Histórico}

Recebido em: 13/06/2021

Revisado por pares em: 16/06/2021

Reformulado e recomendado para publicação: 02/07/2021

Publicado em: 30/07/2021 